\title{
MURRAY STATE

$11-1-2021$

\section{The role of STEM-based sustainability in business and management curricula: Exploring cognitive and affective outcomes in university students}

\author{
Christopher Craig \\ Murray State University, ccraig8@murraystate.edu \\ Elizabeth L. Petrun Sayers \\ RAND Corporation \\ Susan Gilbertz \\ Montana State University Billings \\ Rita Karam \\ RAND Corporation \\ Song Feng \\ University of Arkansas
}

Follow this and additional works at: https://digitalcommons.murraystate.edu/faculty

\section{Recommended Citation}

Craig, C. A., Petrun Sayers, E. L., Gilbertz, S., Karam, R., \& Feng, S. (2021). The Role of Stem-Based Sustainability in Business and Management Curricula: Exploring Cognitive and Affective Outcomes in University Students. Journal of Management Education, 10525629211056316.

This Journal Article is brought to you for free and open access by the Faculty Works at Murray State's Digital Commons. It has been accepted for inclusion in Faculty \& Staff Research and Creative Activity by an authorized administrator of Murray State's Digital Commons. For more information, please contact msu.digitalcommons@murraystate.edu. 


\title{
The role of STEM-based sustainability in business and management curricula: Exploring cognitive and affective outcomes in university students
}

\begin{abstract}
To address deficiencies in STEM and sustainability in business management and intra-university curricula, we developed and implemented an interdisciplinary STEM-based sustainability curriculum at a university in the Western United States. Six classes participated in curricular efforts including in-person and online sections of a business management course, in-person and online sections of a general elective STEM course, and a matched control course for each ( $\mathrm{n}=$ 214). We systematically designed, developed, and implemented curricular interventions - multiweek STEM-based business sustainability modules - using the case teaching method. A comprehensive evaluation with pre- and post-tests was conducted to assess student sustainability cognition and affect. Significant results emerged for sustainability cognition including the environmental, social, and economic dimensions of sustainability. Counterintuitively, student sustainability affect did not improve. However, sustainability cognition and affect were significantly correlated on the post-test for treatment students, an indication that cognitive and affective changes share the same directionality. Discussion, implications, limitations, and future research directions are provided.
\end{abstract}

\section{Please cite as:}

Craig, C.A., Petrun Sayers, E.L., Gilbertz, S., Karam, R., \& Feng, S. (2021). The role of STEMbased sustainability in business and management curricula: Exploring cognitive and affective outcomes in university students. Journal of Management Education. Advanced online publication. https://doi.org/10.1177/10525629211056316 


\section{The role of STEM-based sustainability in business and management curricula: Exploring cognitive and affective outcomes in university students}

\section{Introduction}

Organizations around the world are widely adopting the concept of sustainability (Allen, 2016), necessitating domain proficiency from college graduates and soon to be employees. Sustainability encompasses "ideas, aspirations and values that inspire public and private organizations to become better stewards of the environment and that promote economic growth and social objectives" (Theis \& Tomkin, 2015, p. 7). There are current and future needs for organizational leaders to understand the interconnected relationships shared by the three key sustainability components: economic, environmental, and social well-being (Bagley et al., 2020; Norton \& Thompson, 2014). These needs are exacerbated by grand sustainability-related challenges (e.g., climate change) that require macro-level collaboration and coordination (George et al., 2016). Comparably, place-based organization contributions to grand challengeswhether the contributions are positive or negative — and responses to the localized effects (e.g., disruptions) also require the dynamic understanding of the interconnectedness of sustainability components.

A considerable amount of management education research and practice has been devoted to sustainability. For instance, the Journal of Management Education published six articles in a special issue in 2020 entitled "Sustainability in Management Education." Four of the articles focused on organizational sustainability problem-solving and decision-making. Focal topics include climate change and energy policy (Andre, 2020), occupied building performance (Sroufe, 2020), corporate social responsibility (Urdan \& Luoma, 2020), and organizational scenario planning (Wade \& Piccinini, 2020). Others have also asserted that problem-based 
sustainability learning and decision-making in management education can enhance manager capabilities to address sustainability challenges, including those related to global supply chains (Cole \& Snider, 2019; Thomassen \& Jorgensen, 2020). The variety of context in which educators present sustainability problems is representative of the variety of sustainability challenges organizations encounter. To prepare students for the many challenges managers face, management education should draw from an array of areas such as scientific, technological, economic, ecological, and socio-political domains (Bagley et al., 2020). In other words, interdisciplinary curricula are needed where science, technology, engineering, and mathematics (STEM) intersect with the three component areas of sustainability.

Management education benefits from "embedding sustainability across disciplines," but in practice interdisciplinarity is constrained by a limited knowledge base (e.g., STEM knowledge base) (Annan-Diab \& Molinari, 2017). The result is a limited number of interdisciplinary, STEM-based sustainability program and course offerings in business and management disciplines (AASHE, 2020; Petrun-Sayers et al., 2020). To address this gap, we designed, developed, implemented, and evaluated STEM-based sustainability curriculum in business management and STEM-based courses at a university in the Western United States. Multi-week interdisciplinary STEM, sustainability, and business modules were delivered using the case teaching method. To assess the impact of the curriculum on students, we used a comprehensive longitudinal (i.e., pre-test/post-test design) evaluation with treatment and control groups to assess improvement in student sustainability cognition and affect.

The next two sections overview interdisciplinary curricula and instructional design. Following, we describe the research methods, results, analysis, and provide a discussion and conclusion. 


\section{Interdisciplinary STEM and Sustainability Curricula}

STEM-based sustainability is an interdisciplinary technical area that integrates sustainability knowledge and understanding (i.e., cognition) with STEM competencies (PetrunSayers et al., 2020). Sustainability can be linked to STEM competencies (Hopkinson \& James, 2010; Petrun-Sayers et al., 2020), and "increasingly, high-profile organizations are calling for widespread improvement in undergraduate STEM education. These calls are frequently framed in terms of increasing the number, diversity, and quality of [STEM] graduates" (Borrego \& Henderson, 2014, p. 220). Likewise, Peoples (2009) notes, "We cannot rely exclusively on traditional business expertise ... to make decisions in institutions that rely on science and technology to create products and services" (p. 382). The demand for more interdisciplinary graduates with STEM proficiencies suggests that business schools should adopt a STEM-based sustainability focus.

The number of sustainability courses and programs in management curricula has grown in recent years (AASHE, 2020; Montiel et al., 2017). However, this growth is slow-moving, and several roadblocks remain that could hamper widespread adoption. For instance, sustainability courses are typically (1) elective and not included in core curricula requirements or (2) required and taught from a disciplinary perspective (Bagley et al, 2020; Cole \& Schneider, 2019; Wu et al., 2010). At best, many business programs have students take "traditional" STEM courses, delivered by faculty from other colleges (AASHE, 2020; Personen, 2003). The result is siloed sustainability content delivery based on discipline (Kurland et al., 2010), often devoid of robust business perspectives. To be fair, sustainability issues are complex and often require understandings across multiple disciplines (Annan-Diab \& Molinari, 2017; Pesonen, 2003). 
However, when sustainability is auxiliary, the integration of sustainability into business curricula is incidental and mostly superficial (Boley, 2013).

Kurland et al. (2010) discuss a sustainability course taught by seven faculty members from disciplines including: consumer sciences, geography, management, political science, psychology, recreation and tourism, and urban studies. Each of the instructors developed and delivered their own sustainability section with an overall enrollment of 16 undergraduate students and seven graduate students. The goal of the course was to create seamless interdisciplinary sustainability curriculum. At the end of the semester, however, evaluations suggested that students perceived the course to be multi-disciplinary. The students did not see clear connections between disciplinary sustainability perspectives.

Observed differences based on student discipline pinpoint another challenge. Historically, STEM disciplines such as engineering and technology are more receptive to sustainability curricula than non-STEM disciplines such as business and management (Hopkinson \& James, 2010). For instance, the sustainability course in Kurland et al. (2010) did not include any business or management students despite one of the instructors being from the management discipline. Wilson (2019) notes that engineering students have a stronger sense of responsibility for sustainability challenges than non-STEM students including those from business disciplines. Petrun-Sayers et al. (2020) also note STEM and sustainability education research is dominated by engineering and science disciplines; to date STEM and sustainability research is uncommon in business disciplines. Additionally, business students "either know less about sustainability issues associated with business practices or care less about the issues" (Montiel et al., 2018, p. 173). Academic silos, whether intentional, inadvertent, or stemming from student characteristics 
are barriers to the successful interdisciplinary integration of sustainability (Lidgren et al., 2006; Ralph \& Stubbs, 2014).

To help overcome the barriers to the successful development and implementation of interdisciplinary curriculum, we received an award to design, develop, implement, and evaluate STEM-based sustainability curriculum among business and STEM disciplines (National Science Foundation [NSF], 2020). The NSF funding office supports undergraduate initiatives that "promote novel, creative, and transformative approaches to generating and using new knowledge about STEM teaching and learning to improve STEM education for undergraduate students" (NSF, 2020: par. II). The office acknowledges that "[STEM fields] hold much promise as sectors of the economy where we can expect to see continuous vigorous growth in coming decades" (NSF, 2020: par. I). The award provided the necessary financial support for collaborative, multiyear curricula changes (Benn \& Dunphy, 2009; Lidgren, Rodhe, \& Huisingh, 2006; Ralph \& Stubbs, 2014; Rusinko, 2010; Stekeete, 2009).

\section{Instructional Design}

We implemented STEM-based sustainability curricula in five courses across three universities. However, the scope of this article is limited to six sections of two undergraduate courses offered at a single university during the same term (i.e., Fall 2018). The focal courses are from business management (i.e., Business \& Environment) and STEM-based (i.e., Human Geography) disciplines. Each course included one in-person treatment section, one online treatment section, and one online control section. We did not purposely assign or manipulate the modality of courses as this was not at the discretion of the instructors. However, we assembled control sections to match their associated treatment sections as closely as possible. The 
curriculum was presented as modules that were comparably designed, developed, and implemented using original case studies. Table 1 contains the course descriptions.

[Insert Table 1 about here]

We utilized the ADDIE (analysis, design, development, implementation, evaluation) model of instructional design (Chevalier, 2011). While designers use a variety of frameworks to guide curricula development, most tend to be iterations of the ADDIE model (Rothwell \& Kazanas, 2008). This model seeks to align a training function, in this case involving STEMbased sustainability education, with other efforts to improve performance. Ultimately, the ADDIE model bases instruction on performance requirements in a "dynamic, sequential, and multistage process" (Rothwell \& Kazanas, 2008, p. 59). ADDIE can be used to develop either traditional or online courses. The sequential steps of the ADDIE are outlined below.

\section{ADDIE Stage 1: Analysis}

Beginning in Fall 2017, we undertook a literature review of STEM and sustainability education research and validated the evaluation instrument (e.g., the pre/ and post-test). The literature review explored "curricular gaps specific to STEM and sustainability in the academic literature and in business sustainability program offerings" (Petrun-Sayers et al., p. 82). Results helped the instructors understand the instructional landscape in the United States. For example, we learned that only a small percentage of studies in the field to date included non-STEM undergraduate students in their samples. Overall, this step provided research-based evidence to address the documented curricular gaps in an interdisciplinary manner inclusive non-STEM (i.e., business) and STEM students.

The other primary goal of the analysis phase was to identify and validate measures for evaluation. The literature review revealed weaknesses in existing studies, many of which lacked 
control courses or only delivered post-tests. We designed an evaluation targeting both cognitive and affective learning using pre- and post-tests of matched students in addition to control students that did not participate in the curriculum. Cognitive learning relates to knowledge acquisition and application whereas affective learning "relates to values, attitudes and behaviours and involves learning emotionally" (Shephard, 2008, p. 8).

Cognitive and affective outcomes were included in the evaluation because management educators have established both cognitive and affective learning as necessary but distinct (e.g., Bagley et al., 2020; Montiel et al., 2017, 2018; Shrivastava, 2010). For instance, the management of sustainability in practice requires affect, or passion, towards sustainability (Shrivastava, 2010) yet cognitive sustainability learning does not inherently strengthen affect towards sustainability (Montiel et al., 2017).The cognitive measure used is the Sustainability Knowledge Assessment (ASK) scale (Zwickle et al., 2014), a previously validated instrument that assesses knowledge (i.e., cognition) across the three component areas of sustainability (i.e., environmental, social, economic). Zwickle and others used the ASK scale (e.g., Zwickle et al., 2014; Heeren et al., 2016; Whitley et al., 2018) across multiple doctoral universities in the United States to track yearly campus-wide sustainability literacy for thousands of students. The ASK was used to operationalize sustainability cognition for three primary reasons: (1) it assesses sustainability using a balanced approach where other instruments have focused on environmental sustainability; (2) its non-affective nature allows its use in coordination with affective variables; and (3) it allows for the evaluation of curricular interventions using a pre- and post-test design (Heeren et al., 2016; Whitley et al., 2018; Zwickle et al., 2014; Zwickle \& Jones, 2018).

The affective measure used is the New Ecological Paradigm (NEP; Dunlap et al., 2000) a previously validated scale that captures individual environmental orientation (Dunlap et al., 
2000). Researchers widely utilize the NEP in educational settings, including in coordination with the ASK scale (Heeren et al., 2016). The NEP assesses an individual's ecological worldview as a multi-dimensional proxy for environmental attitudes (Zwickle \& Jones, 2018). Specifically, the NEP allows us to capture an individual's affective state along four dimensions: (1) human rights to modify the natural environment, (2) dynamics of human and natural systems, (3) anthropogenic induced ecological crisis, and (4) availability of natural resources (Dunlap et al., 2000).

To-date, higher education research about sustainability or environmental knowledge and attitudes have primarily been cross-sectional and/or have not included treatment and control groups (e.g., Ajzen et al., 2011; Ataz et al., 2015; Heeren et al., 2016; Whitley et al., 2018; Wilson, 2019). To address these gaps, Zwickle and Jones (2018) called on researchers to introduce more robust research designs that include both pre- and post-tests as well as treatment and control groups to build a clearer understanding of sustainability cognitive and affective outcomes. Addressing Zwickle and Jone's (2018) call, we investigate cognitive and affective sustainability learning using the ASK and NEP before and after STEM-based sustainability interventions.

\section{ADDIE Stages 2-4: Design, Development, and Implementation}

Findings from Kurland et al. (2010) emphasize the lack of connections across disciplines in the pursuit of interdisciplinary sustainability curricula. Thus, the design of curricular materials for all courses applied the shared STEM-based sustainability theme (Petrun-Sayers et al., 2020). The utilization of STEM to explore the economic, environmental, and societal dimensions of sustainability requires interdisciplinarity. The project leadership team collaboratively designed a shared learning objective to "define, explain, and apply economic, environmental, and social 
components of sustainability using STEM-based evidence." Each instructor designed more specific module learning objectives that aligned with the overarching shared learning objective. See Table 2 for module descriptions, learning objectives, and STEM integration. The shared objective directed each instructor to design module learning objectives and develop curricular content to minimally progress through the first three stages of Bloom's revised taxonomy: remember, understand, and apply (Krawthwohl, 2002).

[Insert Table 2]

Development of curricular interventions considered delivery method and curricular content. Guided by Rusinko (2010), courses included two delivery methods: existing and new structures. Existing structures integrate new content whereas new structures involve new standalone curricular additions (Petrun-Sayers et al., 2020; Rusinko, 2010). Each course served as an existing structure depending on the content area. For example, Human Geography acted as an existing structure for business content and Business \& Environment for STEM content. Management educators consider case studies the most important resource for undergraduate sustainability teaching (Aragon-Correa et al., 2017) and business sustainability programs have successfully used the case approach (Benn \& Dunphy, 2009). Thus, new structures were composed of modules (i.e., the curricular interventions) anchored by case studies. Researchbased case studies were developed by each instructor, one of which is published (Craig, 2019) and one of which is was adapted into a full-length book (Gilbertz \& Hall, 2022).

To ensure implementation consistency, and drawing from best practices in case teaching and writing, we developed standard format instructor manuals. The sections in the instructor manuals include (1) teaching content, learning objectives, and timing estimates, (2) teaching notes, (3) STEM integration, (4) student resources, (5) student activities, (6) student assignments, 
and (7) student assessment. Implementation occurred in live and online course sections. The Desire 2 Learn (D2L) learning management system served as a supplemental resource to inperson classes whereas online classes were delivered entirely on D2L. The focal university offers online courses asynchronously, so there was no real-time interaction for online courses. Both instructors made every attempt to deliver the courses as comparably as possible. This was accomplished through standing synchronization meetings and comparing instructional materials in advance. Control students also received the curricular interventions, though they were not exposed to any STEM-based sustainability content prior to the post-test. Assessment included both instructor assessment and evaluation by the external educational evaluator.

\section{ADDIE Stage 5: Evaluation}

Researchers have studied student affective sustainability outcomes over time in higher education (e.g., Strack et al., 2017), though the use of control groups is not common. Likewise, researchers used the ASK to explore the relationships between sustainability cognition and affect, though the studies were cross-sectional (Heeren et al., 2016; Whitley et al., 2018; Zwickle \& Jones, 2018). We connect the cognitive and affective research streams by evaluating the impact of STEM-based sustainability curriculum on cognitive and affective student outcomes over time (i.e., pre- and post-test) using a control group approach. Combined, our pre-test/posttest, treatment/control group evaluation design is more robust than most other STEM and sustainability education studies (Petrun-Sayers et al., 2020).

Evaluating the curriculum, we hypothesize:

Hypothesis 1: Sustainability cognition will improve for students who receive a STEMbased sustainability curricular intervention. 
Hypothesis 2: Sustainability affect will strengthen for students who receive a STEMbased sustainability curricular intervention.

\section{Methodology}

\section{Procedure and Sample}

The study employs a quasi-experimental design using pre- and post-intervention evaluation among a non-random group of students. According to Harris et al. (2006, p. 17), "quasi-experiments are studies that aim to evaluate interventions that do not use randomization" (Harris et al., 2006, p. 17). The design is commonly used in educational settings when randomization of students into treatment and control courses is not feasible. Students received an email with a link to complete a survey using the Qualtrics platform. Pre-tests were completed prior to receiving the intervention and post-tests immediately after during the Fall 2018 term. The survey took approximately 15 minutes to complete. Institutional review board (IRB) approval was obtained prior to surveying students. Only students who completed the pre- and the post-test are included in the sample, a total of 107 students $(n=214)$. The study gathered participants from two in-person treatment courses $(n=33 ; 30.8 \%)$, two online treatment courses $(n=38 ; 35.5 \%)$, and two control courses $(n=36 ; 33.6 \%)$. Please see Table 3 for sample demographics.

[Insert Table 3]

\section{Measures}

Sustainability Knowledge Assessment. The ASK (Zwickle et al., 2014) includes environmental (e.g., "What is the most common cause of pollution of streams and rivers), social (e.g., "Over the past three decades, what has happened to the difference between the wealth of the richest and poorest Americans?"), and economic (e.g., "Which of the following is the most 
commonly used definition of economic sustainability?") questions. The original ASK consists of 16 multiple choice questions developed and validated by Zwickle et al. (2014). Consistent with the current iteration of the scale (Zwickle \& Jones, 2018), we removed a single question from the scale: "Which of the following is the primary reason that gasoline prices have risen over the past several decades in the USA?" For the full list of questions from the ASK, please see Zwickle et al. (2014).

New Ecological Paradigm (NEP). We operationalized affect using seven items from the short-form version of the NEP scale (Dunlap et al., 2000). The reliability for the short-form NEP tends to be lower because the instrument captures a diverse range of environment topics (Nelms, Allen, Craig, \& Riggs, 2017). We observed this with a NEP reliability $(\alpha=.62)$ slightly lower than the reliability Dunlap et al. reported $(\alpha=.68)$. Example items include "Humans have the right to modify the natural environment" and "If things continue on their present course, we will soon experience a major ecological catastrophe" with response categories from (1) strongly disagree to (5) strongly agree.

\section{Data Analysis}

The study dependent variables include the ASK, the NEP, and the environmental, social, and economic subsets of the ASK scale (see Table 4 for descriptives and correlations). Using IBM SPSS version 25, we ran a series of paired-sample t-tests to determine if measures significantly changed from the pre-test to the post-test for treatment and control groups for the ASK, the NEP, and the ASK subsets. Correlations for pre-test and post-test measures are provided (see Table 5). We also used $2 \times 3$ factorial analysis of variance (ANOVA) tests with socio-demographic co-variates. The independent variables were test (i.e., pre- and post-test) and student group (i.e., in-person, online, or control group). Six pairs were formed: pre-test, in- 
person; post-test, in-person; pre-test, online; post-test, online; pre-test, control; post-test, control. ANOVA outputs include F-values and partial eta squared $\left(\eta^{2} p\right)$ (i.e., effect size). Effect sizes range from very small (.01) to large (.8) (Cohen, 1988).

[Insert Tables 4 and 5]

\section{RESULTS AND ANALYSIS}

Hypothesis 1 posits the introduction of STEM-based sustainability interventions will improve student cognition. For both in-person and online classes, the hypothesis is supported. There was significant improvement on the ASK for in-person and online students $(t=-5.51, \mathrm{df}=$ $32, \mathrm{p}=.000$ and $\mathrm{t}=-4.53, \mathrm{df}=37, \mathrm{p}=.000$, respectively) as well as the economic, environmental, and social subsets of the scale (see Table 5 and Figures 1a-d). In-person students improved from $54.5 \%$ to $73.9 \%$, online from $54.4 \%$ to $66.7 \%$, and control students scored approximately the same $(57.0 \%$ to $57.8 \%)$. Students showed the most improvement for the environmental subsect of the ASK where in-person students improved by $19.2 \%$ and online students by $14.5 \%$.

[Insert Figures 1a-d]

Results from the 2x3 ANOVAS also provide support for Hypothesis 1. As shown in Figures 1a-d, significant models emerged where in-person and online students significantly outperformed control students for the $\operatorname{ASK}\left(F=4.25(12,201), p=.000, \eta^{2} p=.20\right)$, the environmental subset $\left(F=3.30(12,201), p=.000, \eta^{2} p=.17\right)$, the social subset $(F=2.79(12$, $\left.201), p=.002, \eta^{2} p=.14\right)$, and the economic subset $\left(F=3.66(12,201), p=.000, \eta^{2} p=.18\right)$. In other words, the intervention had a significant effect on each of the cognitive dependent variables. Socio-demographics co-variants also emerged for the ASK (age and gender), the environmental subset (age), the social subset (age, gender, political party), and the economic 
subset (age and gender). The effect sizes for each of the significant co-variates is small $\left(\eta^{2} p\right.$ range from .02 to .05), meaning significant socio-demographic variables have a small but meaningful influence on each cognitive dependent variable.

Hypothesis 2 posits the introduction of STEM-based sustainability interventions will strengthen student affect. The hypothesis is not supported. As shown in Table 5, paired-sample ttests indicate no significant change for the affective quantitative measure (i.e., NEP) for inperson $(t=-.95, \mathrm{df}=32, \mathrm{p}=.349)$ or online students $(\mathrm{t}=.87, \mathrm{df}=37, \mathrm{p}=.390)$. The $2 \times 3$ ANOVA reveals that gender emerged as a significant co-variate for the NEP, but the model was not significant $\left(F=1.40(12,201), p=.170, \eta^{2} p=.08\right)$. Despite insignificant t-tests and ANOVAS, however, correlation analysis (see Table 4) reveals that NEP is significantly related to ASK for in-person and online students $(\mathrm{R}=.42, \mathrm{p}<.05, \mathrm{R}=.34, \mathrm{p}<.05$, respectively) on post-tests; NEP is also significantly correlated to the ASK social subset for in-person students (R $=.42, \mathrm{p}<.05)$.

\section{DISCUSSION}

If we want a nation where our future leaders, neighbors, and workers have the ability to understand and solve some of the complex challenges of today and tomorrow, and to meet the demands of the dynamic and evolving workforce, building students' skills, content knowledge, and fluency in STEM fields is essential (U.S. Department of Education, 2020: par. I).

Grand and complex sustainability-related challenges require the interdisciplinary consideration of economics, the natural environment, and societal well-being by a diverse body of stakeholders (Bagley et al., 2020; U.S. Department of Education, 2020). This should include university students who will soon become members of the workforce. To develop the future workforce, there is a need in higher education for a systematic approach that facilitates cognitive and affective teaching, learning, and application of 
STEM and sustainability regardless of discipline. Our research-based findings provide support and guidance for those tasked with developing and implementing innovative STEM and/or sustainability curricula to meet current and future workforce demands. Below we discuss two primary contributions including insights into (1) student results and (2) curricula integration.

\section{Student Results}

Our findings provide research-based evidence that STEM-based sustainability interventions can enhance cognitive sustainability outcomes along each sustainability dimension. Based on our evaluation, the results suggest that students enrolled in treatment courses (irrespective of delivery format) significantly improved sustainability cognition whereas there was no significant change for the control group. Results from the ANOVA analysis provide additional empirical evidence that the intervention had a significant effect on treatment students compared to the control group. The evaluation design addressed a gap in the literature by utilizing the ASK and NEP longitudinally with treatment and control groups (Zwickle et al., 2014; Zwickle \& Jones, 2018). To put the ASK score improvement in perspective, Zwickle et al. (2014) reported an overall ASK score of $66.7 \%$ at Ohio State. The pre-tests for our students were over $10 \%$ points lower than those at Ohio State for in-person and online courses $(54.5 \%$ and $54.4 \%$, respectively) but exceeded and tied the score on post-tests $(73.9 \%$ and $66.7 \%$, respectively).

Counterintuitively, the paired-sample t-tests (Table 5) show no significant changes between the pre- and post-test for NEP, thus Hypothesis 2 is not supported. Shephard (2008) contends that progression towards higher-level thinking categories from Bloom's taxonomy (Krawthwohl, 2002) promotes affective learning. However, there are no module objectives that 
move beyond understanding, which demonstrates a potential need for higher-order learning objectives when designing STEM and sustainability curriculum. Our results demonstrate cognitive sustainability improvement, but not to the higher-level that Shephard (2008) equates to strengthening of affective outcomes.

Some assert that sustainability issues require engaged parties to demonstrate affective engagement, passion, and compassion (Beringer et al., 2008; Montiel et al., 2017; Montiel et al., 2018; Shephard, 2008; Shrivastava, 2010; Whitley et al., 2018). This is consistent with the work of Epstein (1994, 2003), which posits behavioral change requires parallel rational (i.e., cognitive) and emotional (i.e., affective) experiences. When designing and developing the curriculum, we utilized the experiential case method to ensure students engaged with real-life experiences (Garvin, 2007; Houde, 2007), in our instance, managerial decision-making related to sustainability challenges. However, we did not explicitly design learning objectives or activities to target student affective learning when engaging with the cases. We acknowledge the instructional design could be enhanced by adding a more proactive engagement feature, such as a service-learning component (Bower, 2011; Rusinko, 2010; Shephard, 2008), where students can personally experience a real-life sustainability-related issue. Despite the NEP not significantly improving from pre- to the post-tests, the results indicate that sustainability affect and cognition were significantly related on post-tests for all treatment students. In other words, higher ASK scores are associated with higher NEP scores and vice versa.

While not the focus of this study, we observed differences between in-person and online courses. For example, while both in-person and online students experienced cognitive improvements, in-person students saw greater improvements. Also, in-person treatment students experienced affective improvement from the pre-test to the post-test, but online treatment 
students experienced declines (Figure 1e). Following COVID-19, as more universities pivot to fully virtual or hybrid schedules, instructors and university administrators should evaluate courses across modalities. While our results suggested that in-person courses were more effective, both in-person and online formats are accompanied with opportunities and challenges. While in-person learning has been the status quo at universities, studies suggest that inperson and online learning can produce comparable outcomes. For example, a review of online learning for undergraduate medical education suggests that it is equally as effective as offline learning (Pei \& Wu, 2019). Another recent multi-year study found no significant differences between in-person and online learners (Paul \& Jefferson, 2019). Specific to an undergraduate management course, Daymont and Blau (2008) also did not observe any performance differences between in-person and online students. Ultimately, student success is encompassed by a myriad of factors outside the instructional content spanning (1) student background characteristics, (2) structural characteristics of an institution, (3) interpersonal interactions with faculty and peers, (4) student perceptions of the learning environment, and (5) the quality of effort students devote to educationally directed activities (Kuh et al., 2007).

In order to understand why in-person students experienced greater cognitive and affective improvements, we would need a more systematic approach to explore the circumstances that exist between in-person versus online learners. For example, while we collected some data relevant to Kuh et al.'s (2007) framework, at present we have an incomplete picture of student success across modalities. For example, literature suggests the importance of a supportive environment which considers the needs of nontraditional students who may choose to take online classes to accommodate work, family obligations, and other responsibilities (Kuh et al., 2007; Paulsen \& McCormick, 2020). Ultimately, for this research, we should consider the 
compositional differences between in-person and online learners, and work to maximize strategies to support student success in both environments.

\section{Curricula Integration}

We also provide guidance on how to successfully integrate and evaluate interdisciplinary STEM-based sustainability (see Table 2 for example learning objectives and STEM integration). We expanded upon Rusinko's (2010) approach by utilizing courses as both existing and new structures for interdisciplinary offerings. Previous researchers faced challenges related to implementing interdisciplinary sustainability curricula due to unique disciplinary beliefs, student characteristics, and the inherent demands of evolving accreditation standards (Bagley et al., 2020; Hopkinson \& James, 2010; Kurland et al., 2010; Montiel et al., 2018). Based on our results, we assert that modules (regardless of discipline) with a shared theme (i.e., STEM-based sustainability) and a common course learning objective can help overcome disciplinary silos. Further, the module approach is less time intensive than creating stand-alone courses, making it more likely for management educators to (1) reach business students who are less likely to take STEM and/or sustainability courses and (2) introduce content accrediting bodies do not explicitly require.

It is encouraging to note that sustainability cognition improvement occurred for existing courses at a small regional university that is experiencing shrinking enrollments and budgetary constraints. Previous researchers note that external funding helps facilitate large-scale curricular efforts (Stekette, 2009; Ralph \& Stubbs, 2014), which was the case for our project. Further, Annan-Diab and Molinari (2017) note that time is a barrier to interdisciplinary courses in management education. For sustainability instructors who do not have the time or funding to develop interdisciplinary program offerings, we provide several pathways to integrate STEM- 
based assignments, modules, or courses. Specifically, we provide two module descriptions, case studies (i.e., Craig, 2019; Gilbertz \& Hall, 2022), and learning objectives (Table 2) where (1) cases can be taught as stand-alone assignments, (2) either module can be integrated into a course, or (3) both modules can be used and/or expanded upon to create a course.

Management education is not devoid STEM or sustainability topics; the interdisciplinary integration of STEM and sustainability knowledge and skills is, however (i.e., STEM-based sustainability). For instance, when conducting an analysis of the performance of occupied buildings — an experiential sustainability problem-solving exercise with STEM implicationsrather than integrating building science into the curriculum, Sroufe (2020) notes that it may be necessary for MBA students to seek out assistance from experts in building science. A common framework used in management education to scan the external business environment is the PESTLE (political, economic, social, technological, legal, environmental) or some variation of the framework (e.g., David \& David, 2016; Wheelen et al., 2018). However, STEM-based skills are not commonly applied to the framework. For example, the environmental analysis (also referred to as ecological analysis) requires students to assess factors such as natural disasters that represent organizational opportunities and threats. What is not required is for students to utilize technological skills and/or assets to access scientific data about the environment that can be analyzed and interpreted alongside internal organizational performance data (see Craig et al. [2019] for an example teaching case study that utilizes an applied STEM approach).

\section{Limitations and Future Research}

While the study includes $107(\mathrm{n}=214)$ matched pairs of students, future studies should employ larger and more diverse samples for future analyses. For example, STEM-based sustainability curricula could be implemented in additional courses throughout intra-university 
curricula and including more universities would bring more demographic, geographic, and institutional diversity. Future research might consider following students over time (i.e., 3 months, 6 months, or 12 months after course completion) to determine the potential influence on workforce decisions such as employment in STEM fields. Such longitudinal evaluation designs will also allow future researchers to assess relationships student sustainability knowledge shares with specific sustainability initiatives, something we were not able to empirically establish with our evaluation design. Another study limitation is that while control students were enrolled in online courses, we did not ask if they were primarily in-person or online students. Future researchers should seek to include both in-person and online course sections and ask students about the mix of face-to-face versus online courses to control for modality preferences. Additional work could also explore the impact of course modalities and compositional differences between in-person and online learners. For example, additional self-report data (via a survey instrument) and collecting more information about environmental factors, such as institutional resources, could provide additional insight into emerging differences between online and in-person courses.

Because the ADDIE model for instructional design was used, it was unlikely that Hypothesis 1 would not be supported, a study limitation. Another limitation is that learning objectives did not move beyond understanding towards higher-level thinking categories from Bloom's taxonomy (Krawthwohl, 2002). Future studies should include such higher-level objectives. Considering the lack of change to affective outcomes (Table 5), follow-up studies are needed that place a stronger emphasis on student affective outcomes and measures. Learning objectives are needed that explicitly address and measure affective outcomes (Shephard, 2008). Service learning, or other co-curricular experience-based opportunities, hold promise to move 
beyond the classroom-based interventions employed in this study for the affective outcomes (Bower, 2011; Rusinko, 2010). Regardless, the design should explicitly include affective objectives and evaluation of interventions should also include pre- and post-tests as well as treatment and control groups where true experimental design is not possible.

Additional measures should be used to evaluate affective aspects of sustainability (Zwickle \& Jones, 2018). For instance, the NEP may not be the best variable to assess the relationship between student sustainability knowledge and sustainability-related affect because of its focus on the environmental dimension of sustainability (Zwickle \& Jones, 2018). When seeking a balanced, robust approach to sustainability researchers should consider more balanced affective measures that give equal weight to each sustainability component area (Zwickle \& Jones, 2018).

\section{Conclusion}

Organizations faced with grand challenges like climate change will require future members of the workforce to be proficient in STEM and sustainability. To address this need, we designed, developed, implemented, and evaluated an interdisciplinary STEM-based curriculum in business and STEM courses allowing us to offer important practical and research-based contributions. We addressed two persistent gaps in management and sustainability education by: (1) reporting three distinct components of educational philosophy including teaching, program design, and student learning (Figueiro \& Raufflet, 2015), and (2) deploying a robust pre- and post-test, treatment- and comparison group evaluation plan (Petrun-Sayers et al., 2020; Zwickle \& Jones, 2018). The classroom-based interventions significantly improved sustainability knowledge but the same did not hold true for the affective outcomes. In the future, affective learning should be explicitly included in curricular design. Ultimately, this research may assist 
business educators, instructors, and administrators who are searching for STEM-based curricula to prepare students for future sustainability challenges. 


\section{REFERENCES}

Ajzen, I., Joyce, N., Sheikh, S., \& Cote, N. G. (2011). Knowledge and the prediction of behavior: The role of information accuracy in the theory of planned behavior. Basic and Applied Social Psychology, 33, 101-117.

Allen, M. W. (2016). Strategic communication for sustainable organizations - Theory and practice. New York: Springer

Andre, R. (2020). Teaching climate leadership: Promoting integrative learning in courses on strong sustainability. Journal of Management Education, 44(6), 766-793.

Annan-Diab, F., Molinari, C. (2017). Interdisciplinarity: Practical approach to advancing education for sustainability and for the Sustainable Development Goals. International Journal of Management Education, 15(2, Part B), 73-83.

Aragon-Correa, J. A., Marcus, A. A., Rivera, J. E., \& Kenworthy, A. L. (2017). Sustainability management teaching resources and the challenge of balancing planet, people, and profits. Academy of Management Learning \& Education, 16(3), 469-483.

Association for the Advancement of Sustainability in Higher Education (AASHE; 2020). Centers for sustainability across the curriculum. Retrieved 3/7/2020 from http://www.aashe.org/partners/centers-for-sustainability-across-the-curriculum/.

Atav, E., Altunoglu, B.D., \& Sonmez, S. (2015). The determination of the environmental attitudes of secondary education students. Procedia Social and Behavioral Sciences, 174, 1391-1396.

Bagley, C. E., Sulkowski, A. J., Nelson, J. S., Waddock, S., \& Shrivastava, P. (2020). A path to developing more insightful business school graduates: A systems-based, experiential 
approach to integrating law, strategy, and sustainability. Academy of Management Learning \& Education, doi: https://doi.org/10.5465/amle.2018.0036.

Benn, S., \& Dunphy, D. (2009). Action research as an approach to integrating sustainability into MBA programs. Journal of Management Education, 33(3), 276-295.

Beringer, A., Wright, T., \& Malone, L. (2008). Sustainability in higher education in Atlantic Canada. International Journal of Sustainability in Higher Education, 9(1), 48-87.

Boley, B. B. (2013). Sustainability in hospitality and tourism education: Towards an integrated curriculum. Journal of Hospitality \& Tourism Education, 23(4), 22-31.

Borrego, M., \& Henderson, C. (2014). Increasing the use of evidence-based teaching in STEM higher education: A comparison of eight change strategies. Journal of Engineering Education, 103(2), 220-252.

Chevalier, R. (2011). When did ADDIE become addie? Performance Improvement, 50(6),10-14. doi: $10.1002 /$ pfi.20221

Cohen, J. (1988). Statistical power analysis for the behavioral sciences $\left(2^{\text {nd }}\right.$ ed.). Hillside, NJ: Lawrence Erlbaum Associates.

Cole, R., \& Snider, B. (2019). Managing in turbulent times: The impact of sustainability in management education on current and future business leaders. Journal of Cleaner Production, 210(10), 1622-1634.

Craig, C.A. (2019). Managing wildfire disasters in the Rocky Mountains. The CASE Journal, 15(2), 78-87. DOI: https://doi.org/10.1108/TCJ-07-2018-0087

Craig, C.A., Petrun Sayers, E.L., Feng, S., \& Kinghorn, B. (2019). The impact of climate and weather on a small tourism business: A wSWOT case study. Entrepreneurship Education and Pedagogy, 2(3): 255-266. DOI: https://doi.org/10.1177/2515127419829399 
David, F.R., \& David, F.R. (2016). Strategic management: A competitive advantage approach, concepts and cases, global edition. Pearson.

Daymont, T., \& Blau, G. (2008). Student performance in online and traditional sections of an undergraduate management course. Journal of Behavioral and Applied Management, $9(3), 275-294$.

Dunlap, R. E., Van Liere, K. D., Mertig, A. G., \& Jones, R. E. (2000). Measuring endorsement of the New Ecological Paradigm: A Revised NEP scale. Journal of Social Issues, 56(3), 425-442.

Epstein, S. (1994). Integration of the cognitive and psychodynamic unconscious. American Psychologist, 49, 709-724.

Epstein, S. (2003). Cognitive-experiential self-theory of personality. In T. Millon \& M. J. Lerner (Eds.), Comprehensive Handbook of Psychology, Volume 5: Personality and Social Psychology (pp. 159-184). Hoboken, NJ: Wiley \& Sons.

Figueiro, P. S., \& Raufflet, E. (2015). Sustainability in higher education: A systematic review with focus on management education. Journal of Cleaner Production, 106, 22-33.

Garvin, D.A. (2007). Teaching executives and teaching MBAs: Reflections on the case method. Academy of Management Learning \& Education, 6(3), 364-374.

George, G., Howard-Grenville, J. H., Joshi, A., \& Tihanyi, L. (2016). Understanding and tackling grand challenges through management research. Academy of Management Journal, 59(6), 1880-1895.

Gilbertz, S.J., \& Hall, D.M. (2022). Bringing sustainability to the ground level: Competing demands in the Yellowstone River Valley. Foreword by A.J. Hoffman. New York: Business Expert Express. 
Harris, A.D., McGregor, J.C., Perencevich, E.N., Furuno, J.P., Zhu, J., Peterson, D.E., \& Finkelstein, J. (2006). Experimental studies in medical informatics. Journal of the American Medical Information Association, 13(1), 16-23.

Heeren, A. J., Sing, A. S., Zwickle, A., Koontz, T. M., Slagle, K. M., \& McCreery, A. (2016). Is sustainability knowledge half the battle? An examination of sustainability knowledge, attitudes, norms, and efficacy to understand sustainable behaviours. International Journal of Sustainability in Higher Education, 17(5), 613-632.

Hopkinson, P., \& James, P. (2010). Practical pedagogy for embedding ESD in science, technology, engineering, and mathematics curricula. International Journal of Sustainability in Higher Education, 11(4), 365-379.

Houde, J., 2007. Analogically situated experiences: Creating insight through novel contexts. Academy of Management Learning \& Education, 6(3), 321-331.

Krawthwohl, D. R. (2002). A revision of Bloom's Taxonomy: An overview. Theory Into Practice, 41(4), 212-218.

Kuh, G. D., Kinzie, J., Buckley, J. A., Bridges, B. K., \& Hayek, J. C. (2007). Piecing together the student success puzzle: Research, propositions, and recommendations. Jossey-Bass.

Kurland, N. B., Michaud, K. E. H., Best, M,. Wohldmann, E., Cox, H., Pontikis, K., \& Vasishth, A. (2010). Academy of Management Learning \& Education, 9(3), 457-476.

Lidgren, A., Rodhe, H., \& Huisingh, D. (2006). A systematic approach to incorporate sustainability into universities and course curricula. Journal of Cleaner Production, 14, 797-809. 
Montiel, I., Delgado-Ceballos, \& Ortiz-de-Mandojana, N. (2017). Mobiles apps for sustainability management education. Academy of Management Learning \& Education, 16(3), 489-493. https://doi.org/10.5465/amle.2017.0184

Montiel, I., Antolin-Lopez, R., \& Gallo, P. J. (2018). Emotions and sustainability: A literary genre-based framework for environmental sustainability management education. Academy of Management Learning \& Education, 17(2), 155-183.

National Science Foundation (NSF; 2020). Improving undergraduate STEM education: Education and human resources (IUSE: ERH). Retrieved 3/7/2020 from https://www.nsf.gov/funding/pgm_summ.jsp?pims_id=505082

Nelms, C., Allen, M.W., Craig, C.A., \& Riggs, S. (2017). Who is the adolescent environmentalist? Environmental attitudes, identity, media usage and communication orientation. Environmental Communication, 11(4), 537-553. DOI: https://doi.org/10.1080/17524032.2016.1275733

Norton, G., \& Thompson, A. (2014). Ethics and sustainable development: The virtues of an adaptive approach to environmental choice. In G. Atkinson, S. Dietz, E. Neumayer and M. Agarwala (Eds.), Handbook of sustainable development (2 ${ }^{\text {nd }}$ ed.) (pp. 105-124). Northhampton, Massachusetts: Edward Elgar Publishing, Inc.

Paul, J., \& Jefferson, F. (2019). A comparative analysis of student performance in an online vs. face-to-face environmental science course from 2009 to 2016. Frontiers in Computer Science, 1(7), 1-9.

Paulsen, J., \& McCormick, A. C. (2020). Reassessing disparities in online learner student engagement in higher education. Educational Researcher, 49(1), 20-29. 
Pei, L., \& Wu, H. (2019). Does online learning work better than offline learning in undergraduate medical education? A systematic review and meta-analysis. Medical Education Online, 24(1), 1666538.

Peoples, R. (2009). Preparing today for a sustainable future. Journal of Management Education, 33(3), 376-383.

Pesonen, H. L. (2003). Challenges of integrating environmental sustainability issues into business school curriculum: A case study from the University of Jyvaskyla, Finland. Journal of Management Education, 27(2), 158-171.

Petrun Sayers, E.L., Craig, C.A., Gilbertz, S., Feng, S., Karam, R., \& Bohman, A. (2020). Advancing STEM-based business sustainability: Mending the curricular gap. Management Teaching Review, 5(1), 82-93. DOI: https://doi.org/10.1177/2379298119852313

Ralph, M., \& Stubbs, W. (2014). Integrating environmental sustainability into universities. Higher Education, 67, 71-90.

Reichardt, C.S. (1979). The statistical analysis of data from nonequivalent group designs. In Cook, T.D., \& Campbell, D.T. (Eds), Quasi-experimentation: Design \& analysis issues for field settings (p.p. 147-205). Boston: Houghton Mifflin

Rusinko, C. A. (2010). Integrating sustainability into management and business education: A matrix approach. Academy of Management Learning and Education, 9(3), 507-519.

Segalas, J., Ferrer-Balas, D., \& Mudler, K.F. (2008). Conceptual maps: Measuring learning processes of engineering students concerning sustainable development. European Journal of Engineering Education, 33(3), 297-306. 
Segalas, J., Mudler, K.F., Ferrer-Balas, D. (2012). What do EESD 'experts' think sustainability is? Which pedagogy is suitable to learn it?: Results from interviews and Cmaps analysis gathered at EESD 2008. International Journal of Sustainability in Higher Education, 13(3), 293-304.

Shephard, K. (2008). Higher education for sustainability: Seeking affective learning outcomes. International Journal of Sustainability in Higher Education, 9(1), 87-98.

Shrivastava, P. (2010). Pedagogy of passion for sustainability. Academy of Management Learning and Education, 9(3), 443-455.

Sroufe, R. (2020). Business schools as living labs: Advancing sustainability in management education. Journal of Management Education, 44(6), 726-765.

Stekette, D. (2009). A million decisions: Life on the (sustainable business) frontier. Journal of Management Education, 33(3), 391-401.

Strack, M., Shephard, K., Jowett, T., Mogford, S., Skeaff, S., \& Mirosa, M. (2017). Monitoring surveying students' environmental attitudes as they experience higher education in New Zealand. Survey Review, 51(366), 257-264.

Theis, T., \& Tomkin, J. (2015). Sustainability: A comprehensive foundation. Retrievable at https://open.umn.edu/opentextbooks/textbooks/sustainability-a-comprehensivefoundation

Thomassen, A.O., Jorgensen, K.M. (2020). John Dewey and continuing management education: Problem-based learning for organizational sustainability. Journal of Workplace Learning, https://doi.org/10.1108/JWL-05-2020-0080.

U.S. Department of Education. (2020). Science, Technology, Engineering, and Math including Computer Science. Retrieved 4/2/2020 from https://www.ed.gov/stem. 
Urdan, M.S., \& Luoma, P. (2020). Designing effective sustainability assignments: How and why definitions of sustainability impact assignments and learning outcomes. Journal of Management Education, 44(6), 794-821.

Wade, B., \& Piccinini, T. (2020). Teaching scenario planning in sustainability courses: The creative play method. Journal of Management Education, 44(6), 699-726.

Wilson, D. (2019). Exploring the intersection between engineering and sustainability education. Sustainability, 11(11), 3134. https://doi.org/10.3390/su11113134

Wheelen, T.L., Hunger, J.D., Hoffman, A.N., \& Bamford, C.E. (2018). Strategic management and business policy: Globalization, innovation and sustainability. Pearson.

Whitley, C. T., Takahashi, B., Zwickle, A., Besley, J. C., \& Lertpratchya, A. P. (2018).

Sustainability behaviors among college students: An application of the VPN theory. Environmental Education Research, 24(2), 245-262.

Wu, Y.J., Huang, S., Kuo, L., \& Wu, W. (2010). Management education for sustainability: A web-based content analysis. Academy of Management Learning \& Education, 9(3), 520531.

Zwickle, A., Koontz, T. M., Slagle, K., \& Bruskotter, J. T. (2014). Assessing sustainability knowledge of a student population. International Journal of Sustainability in Higher Education, 15(4), 375-389.

Zwickle, A., \& Jones, K. (2018). Sustainability knowledge and attitudes - Assessing latent constructs. In W. Leal Filho, r. Marans, \& J. Callewaert (Eds.), Handbook of Sustainability and Social Science Research (pp. 435-451). Cham: Springer International Publishing. https://doi.org/10.1007/978-3-319-67122-2_25 